\title{
DESAFIOS NO ENFRENTAMENTO DA COVID-19: A MEDICINA VETERINÁRIA E SUA ÁREA DE ATUAÇÃO - REVISÃO
}

\section{Maurício Orlando wilmsen; Suélen Dalegrave², João Pedro Grassi de Araújoº}

${ }^{1}$ Doutor, Professor do eixo de Medicina Veterinária Preventiva do Curso de Medicina Veterinária, Pontifícia Universidade Católica do Paraná - PUCPR campus Toledo, Paraná.

${ }^{2}$ Residência em Clínica e Cirurgia de Pequenos Animais, Pontifícia Universidade Católica do Paraná - PUCPR campus Toledo, Paraná.

${ }^{3}$ Residência em Clínica, Cirurgia e Reprodução de Animais de Produção, Pontifícia Universidade Católica do Paraná - PUCPR campus Toledo, Paraná.

DOI: $10.47094 /$ ICONRES.2021/3

\section{RESUMO}

O Sistema Único de Saúde (SUS), tem sido a principal linha de frente no enfrentamento da pandemia de Covid-19. A doença causa uma síndrome respiratória aguda pela infecção com o vírus Sars-cov-2 (Severe acute respiratory syndrome coronavirus 2), o qual possui alto potencial de disseminação entre a espécie humana. A medicina veterinária deixou de ser vista apenas como uma profissão com foco em saúde animal. A atuação do profissional na atualidade ocupa áreas da saúde, desenvolvendo importantes rotas de estudos em epidemiologia, controle de zoonoses e/ou higiene de alimentos, atividades laboratoriais de biologia além de estudos experimentais que contribuem na investigação de animais como possíveis reservatórios para COVID-19. Dessa forma, a atuação desses profissionais nas equipes de Saúde Pública é reconhecida pela OMS, que realça a importância dos conhecimentos adquiridos durante sua formação.

PALAVRA CHAVE: SUS. Sars-CoV-2. OneHealth .

ÁREA: Atenção básica.

\section{INTRODUÇÃO}

Amedicina veterinária possui experiência de longo prazo com odesenvolvimento de estratégias de controle e prevenção de coranaviroses (CoVs), em diferentes espécies animais. Biologicamente, os CoVs são reoconhecidos como vírus de RNA de fita simples, com alta plasticidade genética, capacidade 
de desenvolver mutações pontuais e eventos de recombinação. Esta variação genética é responsável pela emergência contínua de cepas virais com aumento da virulência e tropismos para diferentes tecidos (BUONAVOGLIA et al., 2007). Atualmente, os mesmos são classificados em quatro gêneros distintos: Alphacoronavirus, Betacoronavirus, Gammacoronavirus e Deltacoronavírus, que atuam em espécies domésticas e silvestres, sendo a última um possível indicador de reservatórios naturais. A infecção pelo gênero Alphacoronavírus ocorre em cães e gatos, desenvolvendo a doença entérica o cão (CCoV), com quadro de gastroenterite. Em felinos (FCoV), o acometimento ocorre em filhotes e/ ou adultos, com posterior desenvolvimento de peritonite infecciosa felina (PIF) (seca ou úmida), com evolução fatal na amioria dos animais infectados. O controle e profilaxia das doenças nessas espécies é realizado através de imunização, contudo, para FcoV, a eficácia da vacina é considerada uma insucesso. A nova variante do SARS-CoV-2, é capaz de infectar animais, entretanto, até o momento, o papel dos mesmos frente à disseminação da doença ainda segue sendo investigado. Em humanos, a doença viral é responsável por uma síndrome respiratória aguda com acometimento pulmonar severo, além do vírus comprometer fisiologicamente outros sistemas orgânicos. Tendo em vista o impacto da pandemia mundial de COVID-19 e atuação que saúde pública como um importante eixo de estudos dentro das dinâmicas estabelecidas pela trasmissão de doenças infecciosas de risco zoonótico ou ainda de segurança sanitária, vinculam ao médico veterinário, maior visibilidade a despeito de suas atribuições quanto a resolução de diretrizes relacionadas ao COVID-19 (DECARO et al., 2020). Portanto, o objetivo dessa revisão é apresentar a atuação do médico veterinário inserido na área da saúde e no enfrentamento da pandemia da COVID-19.

\section{MATERIAIS E MÉTODOS:}

Para o desenvolvimento desta revisão integrativa, foram selecionados três bases de dados (Google acadêmico, Periódicos Capes e PubMed), onde os critérios de seleção para a utilização de referências bibliográficas ocorreu através do uso de quatro palavras chaves, em dois diferentes idiomas (português e inglês): medicina veterinária, saúde pública, saúde única e COVID-19, foram utilizados materiais indexados a partir de 2017 até março de 2021.

\section{FUNDAMENTAÇÃO TEÓRICA}

\section{Saúde pública: a medicina veterinária como área da saúde}

Sistemas de saúde pública eficazes requerem uma abordagem interdisciplinar para vigilância, prevenção e controle de doenças de saúde pública. Para tanto, a avaliação da redução do impacto de emergências e desastres em saúde, reconhece a participação integralizada do profissional em planejar e avaliar medidas profiláticas e de controle, adotadas pelas equipes de saúde pública através de atividades estratégicas de vigilância, prevenção e controle de zoonoses (GOMES, 2017). A preoconização das Funções Essenciais de saúde Pública (FESP), são definidas através da Organização PanAmericana de Saúde, com reconhecimento da Organização Mundial da Saúde (OMS). 


\section{Saúde única, NASF e SUS: atuação do médico veterinário no enfrentamento da COVID-19}

A OMS, reconhece que o surto da síndrome respiratória aguda assume o posto de emergência em saúde pública de interesse internacional (GOMES, 2017). Para tanto, a compreensão do termo saúde única (One Health) engloba a atividade integrativa entre a saúde humana, animal, ambiental e a adoção de políticas públicas efetivas para prevenção e controle de enfermidades no âmbito de seu acontecimento.

No Brasil, a medicina veterinária foi implementada na atenção básica (AB), particularmente nos Núcleos de Apoio à Saúde da Família (NASF), através da Portaria nº 2.488, em 2011, que aprova a Política Nacional de AB para o Sistema Único de Saúde (SUS). A atuação do médico veterinário no SUS, como profissional de saúde tem corroborado com a necessidade de ações interdisciplinares, reconhecidas a partir da Resolução 218/1997 do Conselho Nacional de Saúde, como promotora de integralidade em atenção à saúde. Portanto, a atuação do veterinário está embasada na legislação que rege a profissão em vários artigos das competências privativas conforme cita Lei 5517/1968 e o Artigo $6^{\circ}$, que refere o estudo e a aplicação de medidas de saúde pública no tocante às doenças de

animais transmissíveis ao homem. A atuação e inserção no contexto de Saúde Única é citada pela OMS e Organização Mundial da Saúde Animal (OIE).

\section{Epidemiologia de SARS-CoV-2 em animais}

A atuação de médicos veterinários em comunidades científica revelam através de seus resultados de pesquisas a participação de diversos táxons de animais (domésticos e selvagens) como uma possível participação na cadeia epidemiológica da COVID-19. Os animais podem participar como reservatórios ou fontes de infecção/reinfecção a população humana e animal e essas possibilidades integram uma importante linha de pesquisa em diagnósticos laboratorial, estatística, epidemiologia e vacinologia.

As demandas da Covid-19 também se fazem necessária no acompanhamento de animais silvestres. Os estudos em epidemiologia apontam para o acompanhamento de rotas de infecção em animais de vida livre e mantidos em cativeiro, revelando a importância no monitoramento de fauna, frente as alterações clínicas e laboratoriais a nível de vigilância.

\section{CONCLUSÃO}

A atuação do médico veterinário em cenários emergenciais como a pandemia do COVID-19, permite deflagrar importantes áreas de atuação do profissional como as rotas de condução epidemiológica, visando entender a participação de animais como possíveis reservatórios do vírus, além de contribuir exponencialmente na integralidade da conservação da saúde humana e ambiental. A 
medicina veterinária possui uma formação integrativa com outras áreas profissionais, e o resultado de tal integração permite a construção de bases de conhecimentos sólidas e que assumem um importante papel na discussão e fundamentalização de políticas públicas capazes de auxiliar na contenção de futuros desastres biológicos.

\section{REFERÊNCIA}

DAVIS, A.; SHARP, J. Rethinking One Health: emergent human, animal and environmental assemblages.

Social Science \& Medicine, v.258, p.113093, 2020. doi:https://doi.org/10.1016/j. socscimed.2020.113093

DECARO, N.; MARTELlA, V.; SAIF, L. J.; BUONAVOGLIA, C.. COVID-19 from veterinary medicine and one health perspectives: what animal coronaviruses have taught us. Researchs in Veterinary Science, v.131, p.21-23, 2020. doi: https://doi.org/10.1016/j.rvsc.2020.04.009

GOMES, L. B.. Importância e atribuições do médico veterinário na saúde coletiva. Sinapse Múltipla, v.6, n.1,

p.70-75, 2017. 